\title{
LETTERS
}

\section{The conscience rights of Canadian physicians require protection}

I disagree with statements made by Dr. Eric Brown in a letter ${ }^{1}$ in response to an CMAJ editorial by Dr. Diane Kelsall. ${ }^{2}$ The religious and conscience rights of Canadians are not fully protected if they are not free to participate fully in the public square, including the practice of medicine. Physicians may decline to participate in medical assistance in dying (MAiD) because of their religious convictions or because they, like generations of physicians before them, do not believe it is good medicine. Physicians may differ in what they believe is good medicine, most especially in an area as serious as MAiD. Either way, it is not so easy for a family physician who objects to MAiD to change specialties midcareer.

Dr. Brown stated that he cannot imagine why giving general information about MAiD is any different from providing an effective referral for it. Surely, the latter equates with a recommendation for a particular course of action, whereas the former does not. Providing a phone number to the MAiD consul- tation service is a step in the process that some physicians also do not want to take. Because some of our governing authorities may not appreciate the increasing degree of participation in MAiD, from providing information to giving a phone number to facilitating a referral, conscience rights need to be protected by the Canadian Charter of Rights and Freedoms.

To argue that "this is semantics" 1 shows that one has not yet come to fully understand the ethical differences among these actions and what is at stake.

\section{W. Joseph Askin MD}

Sleep physician, Calgary, Alta.; Alberta

Committee for Conscience Protection

Cite as: CMAJ 2018 November 5;190:

E1311. doi: 10.1503/cmaj.70546

\section{References}

1. Brown E. Semantics in referring for medical assistance in dying [letter]. CMAJ 2018;190:E692.

2. Kelsall D. Physicians are not solely responsible for ensuring access to medical assistance in dying. CMAJ 2018;190:E181.

Competing interests: Co-chair, Alberta Committee for Conscience Protection. 